\title{
A conceptual design and numerical analysis of the mixerless urea-SCR system
}

ARTICLE INFO

Received: 14 July 2021

Revised: 26 July 2021

Accepted: 26 July 2021

Available online: 18 August 2021
In the present study, an innovative design of a urea-selective catalytic reduction (SCR) system without conventional mixing elements was developed. The aim was to obtain a high degree of urea decomposition, and uniform ammonia distribution at the inlet to the catalyst, while minimising the liquid film deposition and keeping the compact design. The concept of the design was based on creating high turbulence and elongating the flow paths of the droplets. The design was verified through a series of numerical simulations based on the Reynolds-averaged Navier-Stokes (RANS) approach and a discrete droplet model (DDM) spray representation. The analysis included various operating conditions as well as subcooled and superheated sprays. A uniform ammonia distribution was achieved regardless of the operating points and spray properties. Additionally, in the case of a flash-boiling injection, a further reduction of the wall film was observed.

Key words: $N O_{x}, S C R$, selective catalytic reduction, wall film, CFD

This is an open access article under the CC BY license (http://creativecommons.org/licenses/BY/4.0/)

\section{Introduction}

Current-day emission standards for vehicles impose strict limits of exhaust gas pollutants, inter alia, nitrogen oxides. Selective catalytic reduction is one of the most efficient methods of $\mathrm{NO}_{\mathrm{x}}$ reduction. A urea-water solution (UWS) is sprayed into the flow of the exhaust gases, and then the urea is decomposed to ammonia $\left(\mathrm{NH}_{3}\right)$, required for further $\mathrm{NO}_{\mathrm{x}}$ conversion. Furthermore, diesel engines' exhaust systems occupy a relatively large space and therefore, the maximum reduction of the size is highly desirable $[13,15]$. Modern design concepts comprise close-coupled layouts that due to the minimised distance from the engine enable a higher temperature to be attained in an aftertreatment system, and thus, an increased efficiency of the catalytic conversion. These systems combine diesel oxidation catalysts (DOC), UWS dosing and mixing devices, and selective catalytic reduction coated on particulate filters (SCRoF). However, a reduction in size causes shortening of the UWS droplets' flow paths and residence time, which adversely affects ammonia generation [3, 15, 17]. Efficiency of SCR is highly dependent on the uniformity of the ammonia distribution at the inlet to the catalyst [10, 21]. Static mixing devices are commonly applied to enhance UWS mixing and decomposition, and subsequently to provide a more uniform distribution of ammonia. Nonetheless, significant compression of a system and a presence of mixing elements favour liquid film deposition by spray-wall interactions. Low temperature in the system walls may decrease the UWS temperature below that required for urea crystallisation and make the liquid film turn into solid deposits $[20,26,27]$. The occurrence of deposits is highly undesirable as it leads to a gradual blockage of the SCR, as well as adversely influences the mixing process [29]. On the other hand, the interactions of the droplets with the walls may have a positive effect via the occurrence of additional droplet breakup [23]; consequently leading to a re- duced droplet size, improved dispersion and urea decomposition as well as enhanced mixing [26, 28].

Another challenge for SCR systems is adaptability to diverse exhaust conditions [21] and spray properties. As shown in [11], one of the methods to significantly improve SCR performance is to superheat the UWS prior to the injection and hence, obtain different spray parameters. This phenomenon, also known as flash boiling, reduces the size of the droplets, increases the spray angle, improves the droplets' dispersion and lowers the particles' velocity $[3,30]$. Consequently, water evaporation from the UWS is intensified and the rate of urea decomposition is increased. Therefore, the generation of ammonia and its uniformity are improved, and the liquid film formation is reduced [11].

Numerical and experimental analyses of urea-mixing devices have been presented in multiple studies, most of which were aimed at enhancing ammonia generation and its distribution in compact-sized systems, as well as mitigating the risk of solid deposit formation. Park et al. [24] numerically determined the advantage of turbulent and swirling flow in the mixing process of water spray instead of UWS. The swirl-type mixers enabled the creation of large-scale vortices and therefore, more uniform water distribution than in the case of the small-scale vortex mixer. The authors pointed out the importance of the distance available for the droplets to ensure proper UWS mixing in view of the favourable effect of large-scale vortices. Tan et al. [28] numerically investigated the impact of static mixers on turbulent mixing, interactions of UWS droplets with the walls, and water evaporation. The analysis showed a significant acceleration of urea decomposition due to turbulence and swirling motion, as well as to droplet breakup caused by their collisions with mixing elements. The latter led to a reduction of droplet size and hence the time required for water to evaporate. Kapusta et al. [11] examined the influence of the injection of subcooled and superheated UWS sprays on ammonia uniformity and liquid film deposition in 
an SCR system by numerical analysis. The subcooled spray injection was characterised by droplet breakup due to spray impingement on the mixer blades. The injection angle played a significant role since the superheated UWS spray was strongly deflected when the gas mass flow rate was relatively high, and hence the droplets interacted intensively with the system's wall. Nonetheless, according to their results, even when increased interactions occurred, a lower film deposition was achieved as a consequence of flash boiling. The aforementioned spray blowing caused deterioration of the ammonia distribution. Modification of the injection angle prevented the superheated spray from intensive contact with the system's wall and improved the uniformity of the ammonia distribution. However, this process deteriorated the $\mathrm{NH}_{3}$ distribution when the subcooled spray was deployed again. Thus, the authors concluded that the injector location and inclination may require careful adjustment depending on operating conditions. The application of a superheated spray along with an appropriate injection angle led to an increased uniformity of ammonia distribution and a significant reduction of liquid film, which minimises the risk of solid deposit development. The importance of the injector's location and its inclination in the aftertreatment system with regard to a solid deposit formation was pointed out by $\mathrm{Li}$ et al. [19]. Those parameters were particularly meaningful in the cases of relatively low flow temperatures. Otherwise, the general mixer design was of primary importance. A numerical analysis from Zhang et al. [29], partly validated by experiments, proved that certain implementation of swirling and turbulent flow enables high levels of both ammonia uniformity and velocity uniformity right after the SCR inlet. This required the application of complex mixing elements that were aimed to provide flow changes and droplet breakup through splashing. Sadashiva Prabhu et al. [25] indicated the importance of the mixing zone length and location of the injector, which if properly defined, may provide a higher amount of $\mathrm{NH}_{3}$ at the catalyst inlet. Their numerical analysis pointed out the advantages of an increased spray angle, namely enhanced evaporation of water and a rise in ammonia concentration. Additionally, according to the authors, an optimal angle may lead to a reduction of liquid film deposition; while in general, wider spray plumes result in increased film formation. It is to be noted that increased spray angles are one of the consequences of flash-boiling injections. Numerical and experimental analysis conducted by Cho et al. [5] comprised multiple mixer layouts and decomposition pipes in order to determine the uniformity of the ammonia distribution and the efficiency of the $\mathrm{NO}_{\mathrm{x}}$ conversion in the ureaSCR system. The results proved that the application of static mixers composed of blades significantly enhances ammonia distribution and UWS decomposition due to turbulent vortices. The turbulent flow was particularly advantageous in terms of SCR performance if it occurred close to the inlet of the catalyst. Moreover, the length of the mixing system (decomposition pipe) played a crucial role. A relatively short length impaired the UWS decomposition and mixing, while an excessively long decomposition pipe was exposed to heat loss and reduced the efficiency of the $\mathrm{NO}_{\mathrm{x}}$ conversion in the SCR catalyst. A rise in the flow velocity resulted in lower $\mathrm{NO}_{\mathrm{x}}$ conversion efficiency. However, the system characterised by a higher uniformity of ammonia distribution was less sensitive to changes in gas mass flow rates. Lee [18] performed a numerical analysis of a marine SCR system for various operating conditions and experimentally validated the uniformity of the ammonia distribution. The working principle of that mixing device was based on a partly reversed flow in the mixing zone to enhance the mixing process and increase the residence time of the UWS droplets. In another study, Michelin et al. [22] presented an innovative design for a mixing device for close-coupled applications, based on a spiral gas flow along with tangential UWS injection. The available distance for the UWS decomposition was thereby increased while the compact size was maintained. Their approach showed that the application of blade-based or perforated mixers is not the only way to achieve highly uniform ammonia distribution within a limited space. The design was free from deposit formation. The high-level performance was achieved for both relatively low and large angles of spray plumes. Huang et al. [10] analysed the liquid film and solid deposit formation in a urea-SCR system by numerical simulations. They optimised the mixing device for improved uniformity of ammonia and velocity at the inlet to the SCR, as well as for lower pressure drops. They achieved an improvement in all considered criteria. Moreover, the design led to a reduced liquid film deposition. One of the conclusions was that a rise in the number of mixing vanes can result in higher uniformity of ammonia distribution. Nonetheless, this improvement was advantageous to a certain extent. Lecompte et al. [17] presented a multistage experiment, where the impact of additives in a UWS on deposit formation and ammonia generation was evaluated in a closecoupled system from a passenger car. Relatively low gas mass flow rate and gas temperature caused an increase in the mass of the solid deposits. The ammonia generation was enhanced when the temperature increased.

According to the above studies, much emphasis has been placed on increasing the exhaust system's performance while reducing its size to the maximum extent. However, solid deposit formation in exhaust systems posed a serious concern in most cases. None of those studies proposed and evaluated a design based on the application of a highly turbulent flow field without mixing elements and complex geometry.

The aim of the present work is numerical verification of the innovative mixerless urea-SCR system, to solve the issue of low mixing space availability, minimise deposit formation and provide uniform ammonia distribution for a wide range of operating conditions and injection properties.

\section{Methods}

The performance of the mixing device was evaluated by numerical simulations performed using AVL Fire ${ }^{\mathrm{TM}}$. The main concept of the mixerless SCR system was the development of a highly turbulent flow and large-scale vortices, increasing the flow paths. Nonetheless, the flow was presumed to be adaptable for the Reynolds-averaged NavierStokes (RANS) approach.

The numerical modelling of the spray was based on a discrete droplet model (DDM) [6], in which droplets 
characterised by corresponding properties are grouped into parcels. Each parcel is treated as a single droplet, while droplets within a parcel are randomly dispersed. Groups are then resolved by the Lagrangian approach; while the gas flow field is treated according to the Eulerian approach. This provides a significant reduction of computational time, however it may lead to convergence issues if the mesh resolution is excessively large [7]. The decomposition of the UWS was modelled through Birkhold's approach [2], according to which the water evaporates first. Once the water mass fraction is less than $5 \%$, thermolysis occurs according to Eq. (1):

$$
\left(\mathrm{NH}_{2}\right)_{2} \mathrm{CO} \rightarrow \mathrm{NH}_{3}+\mathrm{HNCO}
$$

The system was numerically tested for conventional (subcooled) and superheated UWS sprays. A flash-boiling effect was simulated by an analogy to a subcooled spray, which was based on the SCR-thermolysis evaporation model. Instead of modelling flash boiling, its implications in the form of the changed spray properties were derived from the experiments [12] and posed input data. According to [11], where such an approach is presented, it results in high compliance with the experiments. The same experimental data was used [11] in the present study. Droplet-wall interactions were characterised by the approach of Kuhnke [16], which identifies four specific regimes. If the wall temperature is higher than approximately $110 \%$ of the droplet saturation temperature, a rebound or a thermal breakup occurs. The latter regime is reached if the impingement velocity is high enough. This regime is particularly desired as it does not contribute to liquid film deposition. Moreover, it provides a droplet breakup, which consequently enhances the droplets' surface area leading to faster urea decomposition and improvement of the mixing process [26]. The size of the entrained droplets was characterised by the model of Kataoka et al. [14].

To properly determine the liquid film deposition in the test system, a wall film module implemented in AVL Fire ${ }^{\mathrm{TM}}$ was applied [1]. The general rule was to determine the film's thickness based on its velocity, which in turn was derived from the film's shear force distribution. The approach proposed by Kuhnke [16] was used to determine any splashing effects, some of which could result in film occurrence. Water evaporation and urea decomposition within the liquid film were evaluated according to Birkhold's approach [2].

Catalytic converters were defined as porous zones, where exclusively a longitudinal flow occurred. Any pressure drop was specified by Forchheimer's formula [8]. The pressure drop coefficients were calculated based on the geometrical data with a reference to physical conditions.

\subsection{Mixerless urea-SCR system}

The present geometry was a close-coupled SCR system, which consisted of a DOC, spray (middle) cone and a SCRoF. The layout of the exhaust system is depicted in Fig. 1. The spray cone was of particular interest since in that part mixing of UWS droplets and products of UWS decomposition with the gas flow occurred.

The main working principle of the proposed design was the development of a highly turbulent and swirled flow in the mixing chamber without any additional static mixing elements. The injector was mounted behind the inlet to the middle cone and it was inclined to extend a droplet path to the impingement plate. The purpose of the impingement plate was twofold. Firstly, it was aimed at providing secondary droplet breakup through the intense impingement. Secondly, it allowed the minimisation of the temperature reductions caused by spray-wall contact, which normally leads to liquid film deposition, as reported in [20] and [26]. The impingement plate was made of a thin metal sheet and was washed around the upper and the bottom side by exhaust gas. Thus, fast temperature recovery between the injections was expected. The section view of the spray cone and its characteristic regions is presented in Fig. 2.

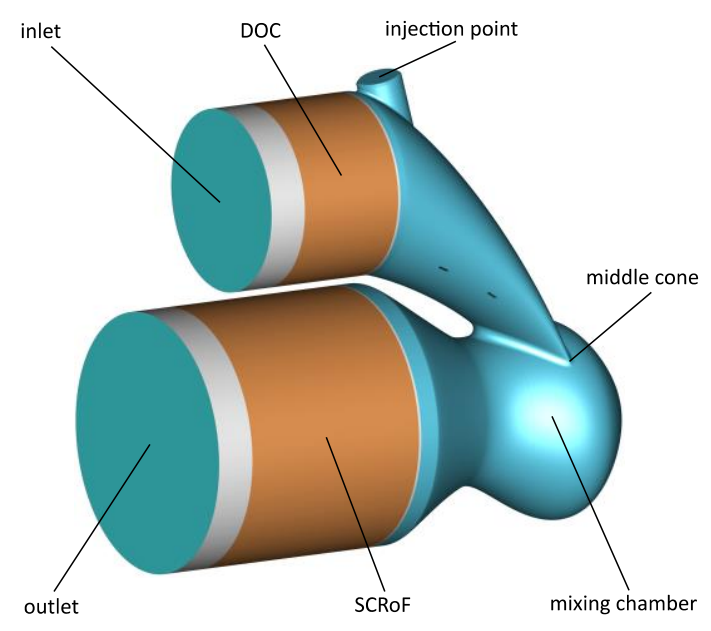

Fig. 1. Geometrical model of the considered close-coupled SCR system

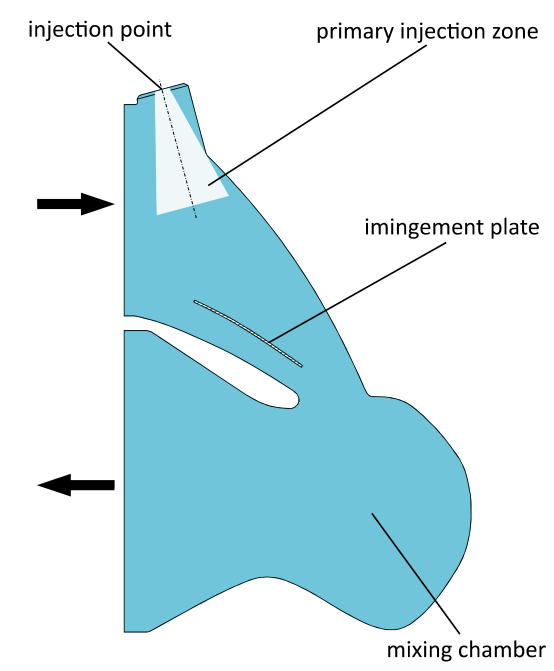

Fig. 2. Section view of the middle cone

\subsection{Numerical cases}

To evaluate the performance of the mixerless urea-SCR system, two operating points were considered. The mass flow rates corresponded to low and high engine loads, namely $100 \mathrm{~kg} / \mathrm{h}$ and $300 \mathrm{~kg} / \mathrm{h}$. The flow temperature was specified to $250^{\circ} \mathrm{C}$ in all cases. The relatively low temperature allowed the investigation of the liquid film deposition risk as according to the studies of Grout et al. [9] and Shahariar et al. [26] the lower the temperature of the gas flow, the more film is developed. The exhaust gas was composed of air and $\mathrm{NO}_{\mathrm{x}}$, with the concentration specified at $150 \mathrm{ppm}$. 
Table 1. Considered cases and corresponding physical conditions

\begin{tabular}{|c|c|c|c|c|c|c|c|}
\hline Case & Gas mass flow & Gas temperature & $\mathrm{NO}_{\mathrm{x}}$ & $\Delta \mathrm{T}$ & $\begin{array}{l}\text { UWS mass } \\
\text { per injection }\end{array}$ & Injection time & $\begin{array}{c}\text { Number } \\
\text { of injections }\end{array}$ \\
\hline 1 & \multirow{2}{*}{$100 \mathrm{~kg} / \mathrm{h}$} & \multirow{4}{*}{$250^{\circ} \mathrm{C}$} & \multirow{4}{*}{$150 \mathrm{ppm}$} & $-20^{\circ} \mathrm{C}$ & $32 \mathrm{~m}$ & $76 \mathrm{mo}$ & \multirow{4}{*}{4} \\
\hline 2 & & & & $+40^{\circ} \mathrm{C}$ & $3.53 \mathrm{mg}$ & $7.0 \mathrm{~ms}$ & \\
\hline 3 & \multirow{2}{*}{$300 \mathrm{~kg} / \mathrm{h}$} & & & $-20^{\circ} \mathrm{C}$ & & & \\
\hline 4 & & & & $+40^{\circ} \mathrm{C}$ & $9.99 \mathrm{mg}$ & $22.8 \mathrm{~ms}$ & \\
\hline
\end{tabular}

The injection frequency was $4 \mathrm{~Hz}$ and the simulated injection corresponded to the spray formed by a commercial UWS injector (Bosch 0444025030). Therefore, the amount of injected UWS and injection duration were determined in accordance with the previous measurements [11, 12] and the molar ratio from the equations of thermolysis (Eq. (1)) and hydrolysis (Eq. (2)):

$$
\mathrm{HNCO}+\mathrm{H}_{2} \mathrm{O} \rightarrow \mathrm{NH}_{3}+\mathrm{CO}_{2}
$$

All the cases were tested for UWS temperatures corresponding to degrees of superheat of $-20^{\circ} \mathrm{C}$ and $+40^{\circ} \mathrm{C}$. The degree of superheat $\Delta \mathrm{T}$ was defined as the difference between the actual temperature of the UWS ( $\mathrm{T}_{\mathrm{UWS}}$ ) and its saturation temperature ( $\mathrm{T}_{\mathrm{S} \text { uws }}$ ), according to Eq. (3). The UWS saturation temperature under standard conditions is $103^{\circ} \mathrm{C}$ [4], and this value was used to calculate the degree of superheat.

$$
\Delta \mathrm{T}=\mathrm{T}_{\mathrm{UWS}}-\mathrm{T}_{\mathrm{S} \text { UwS }}
$$

According to the simulations' results, large-scale eddies were observed, and an entirely steady flow was unreachable. Therefore, the results were presumed to depend on the starting point of the injection (namely on the flow conditions when the injection starts), and only a few injections were considered. Simulation of multiple UWS injections would result in lower time dependence, however, this approach was rejected due to the substantial computational time. Instead, a series of four injections were simulated at three different starting points. The offset between the following starting points was specified to $0.5 \mathrm{~s}$, and it was presumed in order to avoid the results' correlation with the large-scale-vortex fluctuations. All the considered cases are presented in Table 1.

The mesh for the numerical analysis was generated in AVL FIRETM $M$ software and consisted of polyhedral and prism elements. The basic cell size was specified at $6 \mathrm{~mm}$. The primary injection zone, where the highest number density of spray droplets occurred, was meshed with $5 \mathrm{~mm}$ sized cells. The surface cell size on the impingement plate was reduced to $3 \mathrm{~mm}$ as the accuracy of wall film modelling greatly depends on the mesh resolution in the impingement zone and the adjacent wetting regions.

\section{Results and discussion}

The performance of the mixerless SCR system was evaluated by numerical methods. In order to confirm the versatility of the design, two operating points were considered, each of them characterised by the two diverse types of UWS injections: conventional (subcooled) and superheated. The exhaust gas flow was characterised by periodic breakdowns despite the constant mass flow rate.
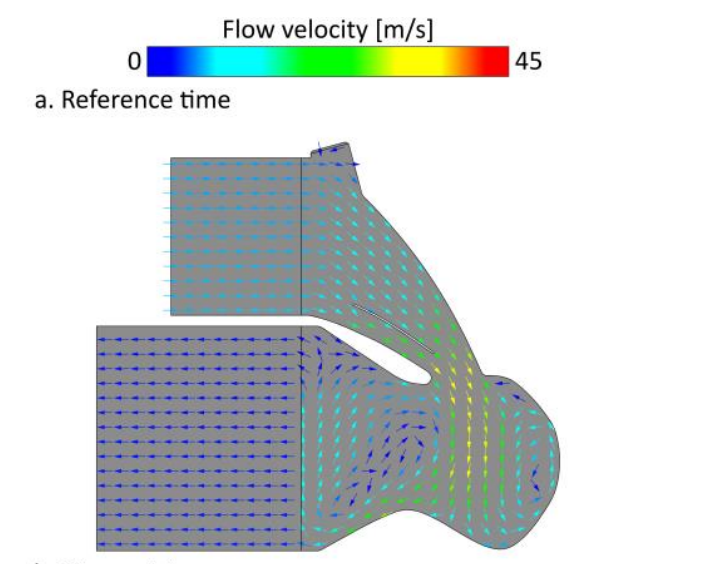

b. Time: $+0.4 \mathrm{~s}$

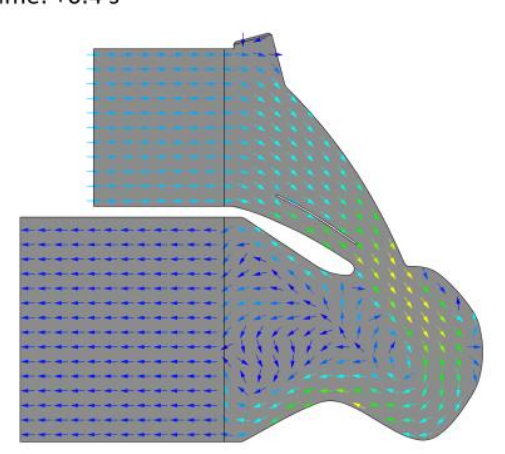

c. Time: $+0.5 \mathrm{~s}$

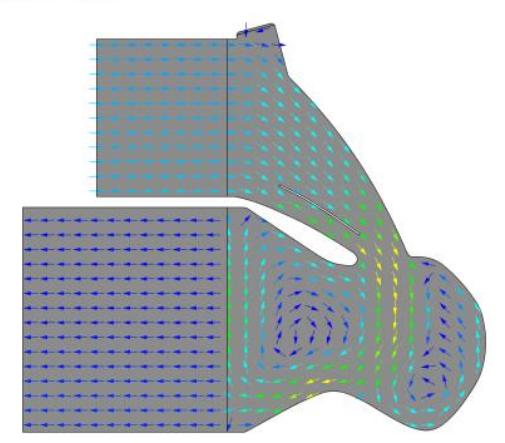

Fig. 3. Velocity fluctuations presented by flow velocity vectors - three particular layouts, mass flow rate: $300 \mathrm{~kg} / \mathrm{h}$

The flow was accelerated in the constriction, then expanded in the mixing zone where it was decelerated, and the streamlines were curled due to geometrical constraints. Throughout most of the simulation time, the flow was split into two main swirl zones: one in the back, and the other located upstream of the SCR inlet (Fig. 3a). However, the flow entering the mixing chamber was gradually deflected backwards, and the frontal swirl motion was diminished (Fig. 3b), until a breakdown occurred (Fig. 3c). Then, the flow was rapidly deflected forwards and returned to the initial state, demonstrating strong fluctuations. This indicated that the LES approach would be more appropriate to 
fully recognise these effects. However, at this point, due to computational limitations and the need for initial evaluation of the concept, the studies were continued with the RANS method.

The application of the mixing chamber and the related swirling nature of the flow were intended to result in some strong turbulence. The turbulence kinetic energy in the mixing chamber at three particular simulation times (Fig. 4), corresponding to the velocity fields presented in Fig. 3, confirmed the occurrence of large-scale vorticity. In reference to the order of magnitude of the flow velocity $\left(10^{1} \mathrm{~m} / \mathrm{s}\right)$, the turbulence kinetic energy was substantial, which enabled the prediction of the high-level mixing efficiency of the presented design.
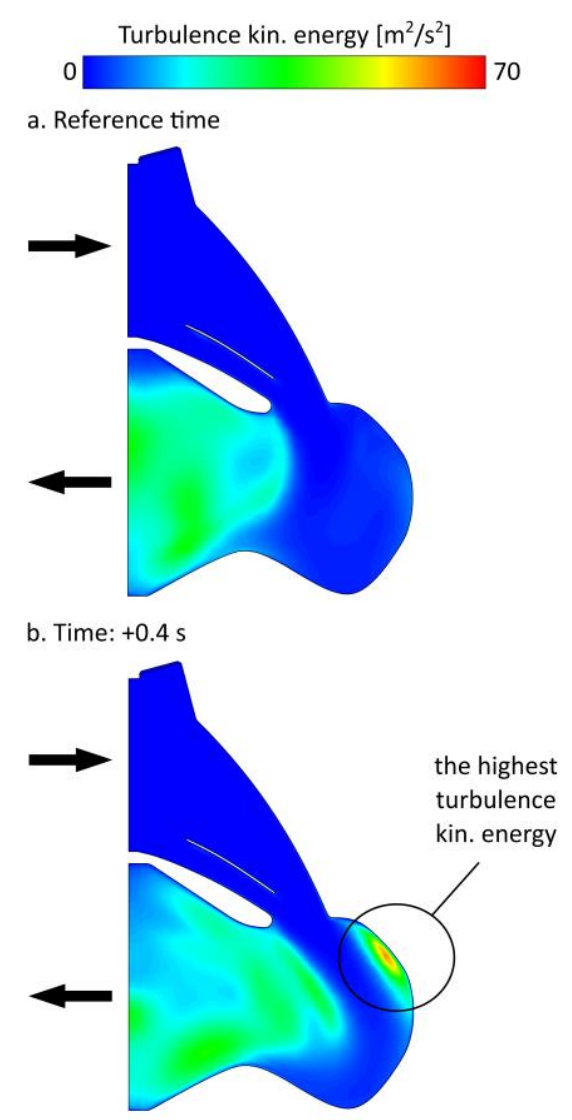

c. Time: $+0.5 \mathrm{~s}$

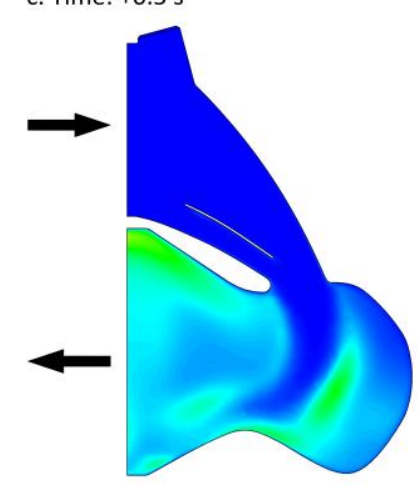

Fig. 4. Turbulence kinetic energy, mass flow rate: $300 \mathrm{~kg} / \mathrm{h}$; a. prevailing layout, b. flow breakdown, c. flow recovery

Since the flow field was subjected to fluctuations, each of the cases was evaluated thrice. Namely, with different delays until the first injections were considered; each of them was characterised by a $0.5 \mathrm{~s}$ offset.

One of the key factors influencing the performance of SCR systems is liquid film occurrence. It leads to a solid deposit formation and may substantially lower $\mathrm{NO}_{\mathrm{x}}$ conversion efficiency. Therefore, one of the evaluated quantities was the total mass of liquid film developed inside the whole system. The individual results for all the subcases of the $100 \mathrm{~kg} / \mathrm{h}$ and $300 \mathrm{~kg} / \mathrm{h}$ cases are presented in Fig. 5 and Fig. 6, as follows.

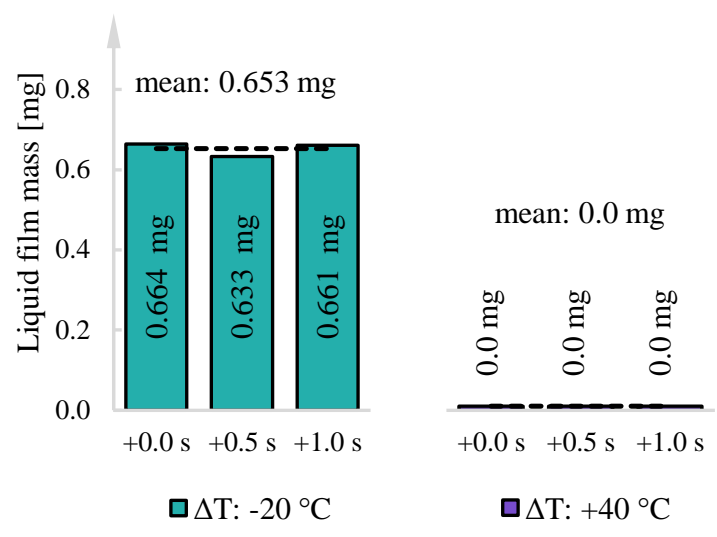

Fig. 5. Total liquid film mass at a gas mass flow rate of $100 \mathrm{~kg} / \mathrm{h}$, all subcases listed

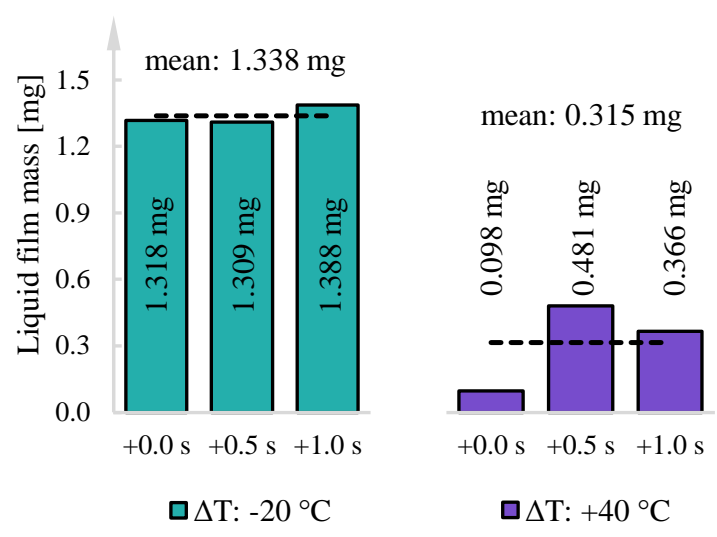

Fig. 6. Total liquid film mass at a gas mass flow rate of $300 \mathrm{~kg} / \mathrm{h}$, all subcases listed

The resulting values indicated a relatively low liquid film mass inside the system. An increased gas mass flow rate led to a rise in film mass, which resulted from increased injection time and hence a longer time when the droplet-wall collisions occurred. The liquid film was observed mostly on the plate due to intense local cooling caused by liquid impingement. It particularly concerned the subcooled injection characterised by a narrower spray plume and higher impingement velocity. The constriction above the mixing chamber caused intensified droplet-wall contacts. However, no film was formed there because of the high droplet dispersion and low degree of local cooling. Trace amounts of the film were deposited in the mixing chamber and near the injector. The latter resulted directly 
from the design's features. The close distance from the nozzle to the wall led to some interactions of the smallest droplets and additionally, the low flow velocity in this region intensified the deposition. Those trace amounts of wall film prevailed in the case of flash-boiling injection and high gas mass flow rate, where no film occurred on the plate. The lowest observed temperature in the vicinity of the upper surface of the impingement plate after the start of the injection (ASOI) for various UWS conditions and the highest gas mass flow rate is presented in Fig. 7. The decline of the local temperature in the case of the subcooled injection was much higher than for the superheated injection. The superheated spray was characterised by a reduced droplet size and increased spray angle. The smaller droplets were then shifted farther downstream and were more dispersed, which influenced the lower temperature drops. It is to be noted that droplet-plate collisions started later in the case of the flash-boiling injection as the droplet velocity was lower. Therefore, the maximum temperature drop in the case of the superheated-liquid injection occurred approximately $29 \mathrm{~ms}$ ASOI, compared to $10 \mathrm{~ms}$ ASOI for the conventional injection. The distribution of the temperature corresponded to the locations of the droplet-wall collisions and wetting regions, as well as to the liquid film deposition, which is consistent with the analysis of Li et al. [19]. Consequently, the application of the flash-boiling injection resulted in a total reduction of the liquid film in low-mass-flow rated conditions and a substantial reduction for the higher mass flow rate (Figs 5-6).
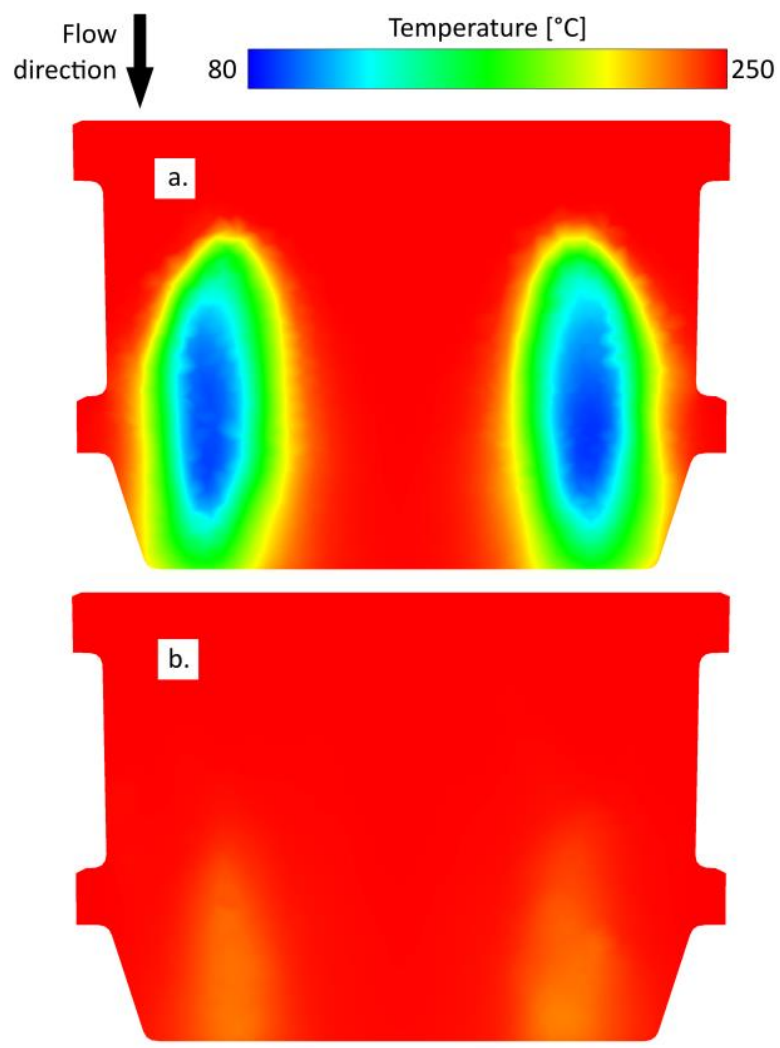

Fig. 7. The local temperature in the vicinity of the impingement plate mapped on its surface at the time of the maximum temperature drop, mass flow rate: $300 \mathrm{~kg} / \mathrm{h}$; a. subcooled spray, $10 \mathrm{~ms}$ ASOI; b. superheated spray, $29 \mathrm{~ms}$ ASOI
Since ammonia is a reducing agent for $\mathrm{NO}_{\mathrm{x}}$ compounds in SCR systems and its uniform distribution is crucial for the high performance of those systems, the quality of mixing was assessed based on the dispersion of $\mathrm{NH}_{3}$ approximately $10 \mathrm{~mm}$ from the SCR's inlet (inside the porous medium). The uniformity was described by the uniformity index of ammonia distribution $\mathrm{UI}_{\mathrm{NH}_{3}}$ according to Eq. (4):

$$
\mathrm{UI}_{\mathrm{NH}_{3}}=1-\frac{\sum\left|\mathrm{c}_{\mathrm{iNH}_{3}}-\mathrm{c}_{\mathrm{NH}_{3}}\right| \cdot \mathrm{A}_{\mathrm{i}}}{2 \cdot \mathrm{c}_{\mathrm{NH}_{3}} \cdot \sum \mathrm{A}_{\mathrm{i}}}
$$

where: $A_{i}$ was a surface of a given mesh element; $\mathrm{c}_{\mathrm{NH}_{3}}$ was the mean $\mathrm{NH}_{3}$ concentration; and $\mathrm{c}_{\mathrm{i} \mathrm{N}} \mathrm{H}_{3}$ was the concentration of $\mathrm{NH}_{3}$ in the corresponding mesh element.

The resulting values of the ammonia uniformity index are presented in Fig. 8 and Fig. 9 for the cases of $100 \mathrm{~kg} / \mathrm{h}$ and $300 \mathrm{~kg} / \mathrm{h}$ gas mass flow rates.

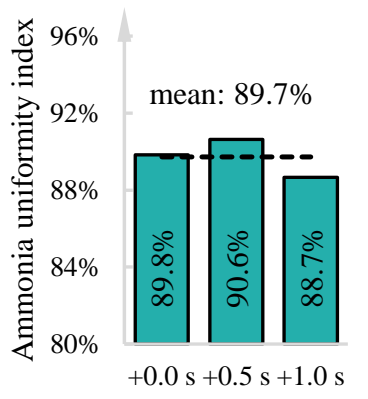

mean: $92.2 \%$

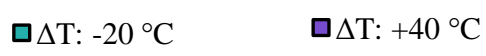

Fig. 8. Ammonia uniformity index at a gas mass flow rate of $100 \mathrm{~kg} / \mathrm{h}$, all subcases listed

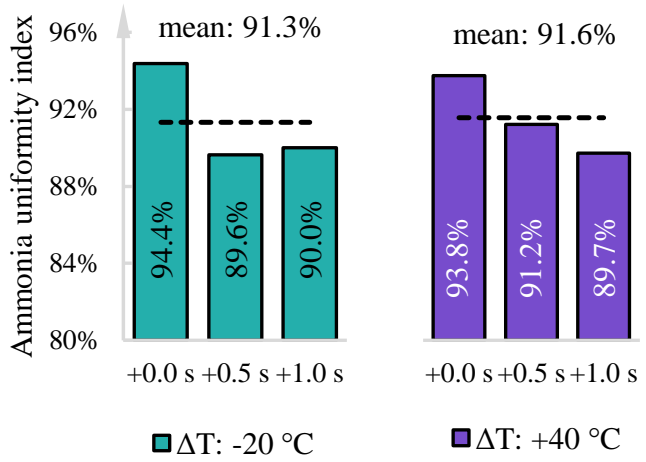

Fig. 9. Ammonia uniformity index at a gas mass flow rate of $300 \mathrm{~kg} / \mathrm{h}$, all subcases listed

Despite the lack of mixing elements, the uniformity of the ammonia distribution reached an excellent and comparable level regardless of the gas mass flow rate. Firstly, the flow in the mixing chamber was subjected to intense turbulence and streamline deflections according to the predictions. Streamlines of the exhaust gas flow are presented in Fig. 10. 


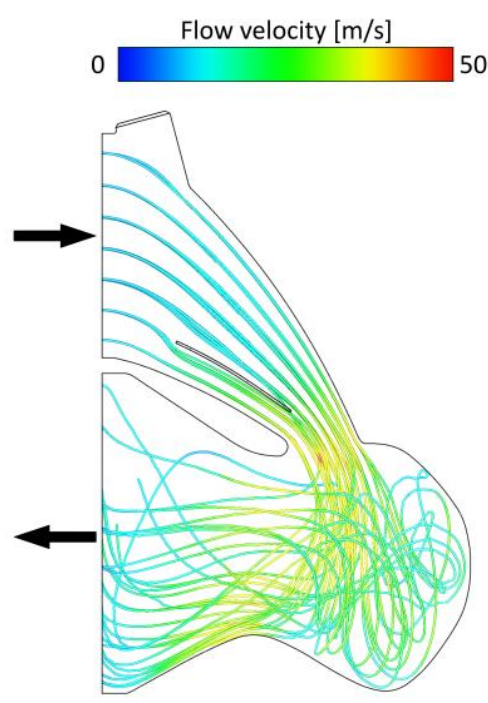

Fig. 10. Velocity streamlines inside the middle cone at a gas mass flow rate of $300 \mathrm{~kg} / \mathrm{h}$

Secondly, the inclination of the injector and the swirl motion in the mixing chamber significantly increased the length of the droplets' paths to reach the impingement plate and the porous medium, respectively. Since the UWS residence time was increased, water could evaporate to a higher extent and the urea conversion efficiency was increased. Another reason for high ammonia uniformity at the inlet to the SCR was a substantial reduction in droplet size caused by impingement on the top surface of the plate (Fig. 11). Location of the plate and local gas velocity favoured a relatively high impingement velocity. Consequently, the spray-wall interaction regimes corresponded to splash and thermal breakup for the subcooled spray, while rebound and thermal breakup for the superheated spray followed Kuhnke's description [16], which allowed for droplet breakups. Smaller droplets led to improved water evaporation and urea decomposition. Thus, the ammonia generation and mixing were enhanced.

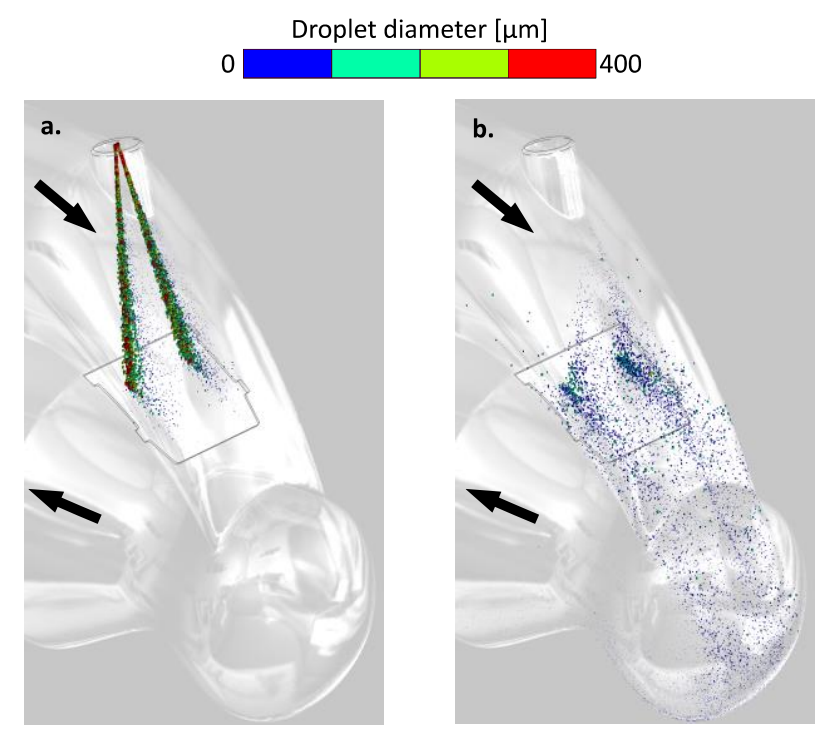

Fig. 11. Spray impingement, subcooled injection; a. $10 \mathrm{~ms}$ ASOI, droplet size scale: 10; b. $29 \mathrm{~ms}$ ASOI, droplet size scale: 15
Ammonia dispersion was improved by flash boiling, particularly in the case of a low gas mass flow rate. When the gas mass flow rate was increased, improvement of the ammonia uniformity by flash boiling was marginal. It resulted from strong spray interactions with the gas, and thus the droplets were transferred onto the walls. Since the size of the droplets was reduced, the surface-to-volume ratio was increased making the droplets more sensitive to the aerodynamic drag. The droplets quickly exchanged momentum with the exhaust gases and changed their trajectories. However, the size reduction also shortened the time required for the UWS to decompose and finally, the ammonia uniformity after the SCR's inlet remained at a similar level.

Actually, the presented mixing device was characterised by a high performance in the case of both conventional and flash boiling UWS injections. The latter was particularly advantageous for low engine-load conditions. Nevertheless, the system was universal, and provided high mixing regardless of the UWS temperature.

\section{Conclusions}

The results obtained during the numerical simulations showed that the system was characterised by the large-scale vortices in the turbulent flow. To fully recognise these unsteady changes and verify the results obtained with the RANS approach, the LES (large eddy simulations) method should be applied. Thus, the results presented here should be considered as an initial evaluation of the newly presented concept.

The simulations performed suggested that it is possible to reach high uniformity of ammonia concentration before the inlet to the SCR catalyst at a significantly limited distance, without implementing static mixing elements into the middle cone. High mixing efficiency has been achieved by generating a very turbulent flow in the mixing zone. The developed flow field also allowed only a very low liquid film deposition, despite the relatively low temperature of the exhaust gas. This was caused by the initial flow acceleration, which favoured the transport of the injected or splashed droplets into the mixing chamber, and subsequent turbulent mixing. Moreover, numerical simulations showed a significant reduction of the total wall film in the case of increased temperature of the injected UWS causing the flash-boiling phenomenon. The system operating under such conditions was characterised by a significant reduction of the risk of the deposits' formation. In the case of both subcooled and superheated liquids, it was possible to reduce the cooling of the system walls caused by the spray-wall interactions, as well as to enhance the consequent temperature recovery of the wetted walls. This effect was achieved by implementing a thin impingement plate (resulting in relatively low volume and large surface), which was located so that the hot gases washed it from both sides.

The CFD calculations suggested that the tested system is able to work effectively at a wide range of operating points. For both mass flow rates of 100 and $300 \mathrm{~kg} / \mathrm{h}$, high uniformity of ammonia after the inlet to the SCR catalyst was achieved due to intensive turbulent mixing and secondary breakup caused by droplet-plate collisions. It was found that the device ensures excellent operation under the condi- 
tions of a subcooled-liquid injection and when the flashboiling phenomenon occurs.

The prototype mixing system has compact dimensions, thanks to which it is possible to mount DOC and SCR catalysts close to each other in accordance with the trend of close-coupled systems. Moreover, the internal structure is considerably simplified compared to most of the systems which implement static mixing devices.

The presented concept of the mixing device in the SCR system has features that offer potential improvements to the currently used systems. However, to obtain a complete picture of the functioning of the device, further research using the LES approach and the creation of an actual proto- type, which would enable experimental tests and the verification of the system's performance, are necessary.

\section{Acknowledgements}

The project leading to this application has received funding from the National Centre for Research and Development (NCBiR), grant no. MAZOWSZE/0101/19-00, programme Ścieżka dla Mazowsza, project budget: 9880490.25 PLN.

Numerical simulations were performed using AVL FIRE $^{\text {TM }}$ software under AVL University Partnership Program.

\section{Nomenclature}

$\mathrm{A}_{\mathrm{i}} \quad$ surface of a given (i-th) mesh element

ASOI after start of the injection

$\mathrm{c}_{\mathrm{NH} 3}$ mean $\mathrm{NH}_{3}$ concentration

$\mathrm{c}_{\mathrm{i} \mathrm{NH}}$ mean $\mathrm{NH}_{3}$ concentration of a given (i-th) mesh element

CFD computational fluid dynamics

DDM discrete droplet model

DOC diesel oxidation catalyst

LES large eddy simulations

$\mathrm{NH}_{3}$ ammonia
$\mathrm{NO}_{x} \quad$ nitrogen oxides

RANS Reynolds-averaged Navier-Stokes

SCR selective catalytic reduction

SCRoF selective catalytic reduction on particulate filter

$\mathrm{T}_{\text {UWS }}$ temperature of UWS

$\mathrm{T}_{\mathrm{S} \text { UWS }}$ saturation temperature of UWS

$\mathrm{UI}_{\mathrm{NH} 3}$ ammonia uniformity index

UWS urea-water solution

$\Delta \mathrm{T} \quad$ degree of superheat

\section{Bibliography}

[1] AVL LIST GmbH FIRE TM 2019.2 Wall Film Module User Guide. Wall Film Module. 2019

[2] BIRKHOLD, F. Selektive katalytische Reduktion von Stickoxiden in Kraftfahrzeugen: Untersuchung der Einspritzung von Harnstoffwasserlösung. 2007, 15(6), 893900.

[3] BRIZI, G., POSTRIOTI, L. Experimental analysis of SCR spray evolution and sizing in high-temperature and flash boiling conditions. SAE International Journal of Fuels and Lubricants. 2019, 12(2), 87-107. https://doi.org/10.4271/04-12-02-0006

[4] BROCKLEY GROUP LTD. Safety data sheet BlueCat AdBlue. 2014

[5] CHO, Y.S., LEE, S.W., CHOI, W.C. et al. Urea-SCR system optimization with various combinations of mixer types and decomposition pipe lengths. International Journal of Automotive Technology. 2014, 15(5), 723-731. https://doi.org/10.1007/s12239-014-0075-x

[6] DUKOWICZ, J.K. A particle-fluid numerical model for liquid sprays. Journal of Computational Physics. 1980, 35(2), 229-253.

https://doi.org/10.1016/0021-9991(80)90087-X

[7] EDELBAUER, W. Coupling of 3D Eulerian and Lagrangian spray approaches in industrial combustion engine simulations. Journal of Energy and Power Engineering. 2014, 8(1). https://doi.org/10.17265/1934-8975/2014.01.022

[8] FORCHHEIMER, P. Wasserbewegung durch boden. Zeitschrift des Vereins deutscher Ingenieure, 45th edition. 1901.

[9] GROUT, S., BLAISOT, J.-B., PAJOT, K. et al. Experimental investigation on the injection of an urea-water solution in hot air stream for the SCR application: Evaporation and spray/wall interaction. Fuel. 2013, 106, 166-177. https://doi.org/10.1016/j.fuel.2012.09.022
[10] HUANG, H., CHEN, Y., LI, Z. et al. Analysis of deposit formation mechanism and structure optimization in ureaSCR system of diesel engine. Fuel. 2020, 265, 116941. https://doi.org/10.1016/j.fuel.2019.116941

[11] KAPUSTA, Ł.J., ROGOZ, R., BACHANEK, J. Experimental and numerical study to evaluate the effect of flash boiling on urea-water solution sprays and SCR system performance. Atomization and Sprays. 2021, 31(5), 89-117. https://doi.org/10.1615/AtomizSpr.2021035461

[12] KAPUSTA, Ł.J., ROGOZ, R., BACHANEK, J. et al. Lowpressure injection of water and urea-water solution in flashboiling conditions. SAE International Journal of Advances and Current Practices in Mobility. 2020, 3(1), 365-377. https://doi.org/10.4271/2020-01-2110

[13] KAŠPAR, J., FORNASIERO, P., HICKEY, N. Automotive catalytic converters: current status and some perspectives. Catalysis Today. 2003, 77(4), 419-449. https://doi.org/10.1016/S0920-5861(02)00384-X

[14] KATAOKA, I., ISHII, M., MISHIMA, K. Generation and size distribution of droplet in annular two-phase flow. Journal of Fluids Engineering. 1983, 105(2), 230-238. https://doi.org/10.1115/1.3240969

[15] KOEBEL, M., ELSENER, M., KLEEMANN, M. UreaSCR: a promising technique to reduce NOx emissions from automotive diesel engines. Catalysis Today. 2000, 59(3), 335-345. https://doi.org/10.1016/S0920-5861(00)00299-6

[16] KUHNKE, D. Spray/wall-interaction modelling by dimensionless data analysis. 2004.

[17] LECOMPTE, M., OBIOLS, J., CHEREL, J. et al. The benefits of diesel exhaust fluid (DEF) additivation on ureaderived deposits formation in a close-coupled diesel SCR on filter exhaust line. SAE International Journal of Fuels and Lubricants. 2017, 10(3), 864-877. https://doi.org/10.4271/2017-01-2370 
[18] LEE, C. Numerical and experimental investigation of evaporation and mixture uniformity of urea-water solution in selective catalytic reduction system. Transportation Research Part D: Transport and Environment. 2018, 60, 210-224. https://doi.org/10.1016/j.trd.2017.04.015

[19] LI, M., ZHANG, Y., LIU, X. et al. Numerical investigation on the urea deposit formation process in a selective catalytic reduction system of a diesel engine based on a fluid-solid coupling method. ACS Omega. 2021, 6(8), 5921-5932. https://doi.org/10.1021/acsomega.1c00021

[20] LIAO, Y., DIMOPOULOS EGGENSCHWILER, P., RENTSCH, D. et al. Characterization of the urea-water spray impingement in diesel selective catalytic reduction systems. Applied Energy. 2017, 205, 964-975. https://doi.org/10.1016/j.apenergy.2017.08.088

[21] MAIZAK, D., WILBERFORCE, T., OLABI, A.G. DeNOx removal techniques for automotive applications - a review. Environmental Advances. 2020, 2, 100021. https://doi.org/10.1016/j.envadv.2020.100021

[22] MICHELIN, J., GUILBAUD, F., GUIL, A. et al. Advanced compact SCR mixer: BlueBox. SAE Technical Paper 201401-1531. 2014. https://doi.org/10.4271/2014-01-1531

[23] NISHAD, K., STEIN, M., RIES, F. et al. Thermal decomposition of a single AdBlue ${ }^{\circledR}$ droplet including wallfilm formation in turbulent cross-flow in an SCR system. Energies. 2019, 12(13), https://doi.org/10.3390/en12132600

[24] PARK, T., SUNG, Y., KIM, T. et al. Effect of static mixer geometry on flow mixing and pressure drop in marine SCR applications. International Journal of Naval Architecture
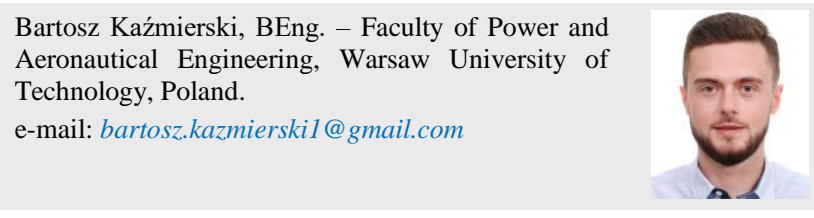

Krzysztof Górka, BEng. - Faculty of Power and Aeronautical Engineering, Warsaw University of Technology, Poland.

e-mail:krzysztof.gorka21@gmail.com and Ocean Engineering. 2014, 6(1), 27-38.

https://doi.org/10.2478/IJNAOE-2013-0161

[25] PRABHU, S.S., NATESAN, K., SHIVAPPA NAYAK, N. Effect of UWS spray angle and positioning of injector on ammonia concentration in urea-SCR system. Materials Today: Proceedings. 2021, https://doi.org/10.1016/j.matpr.2021.03.026

[26] SHAHARIAR, G.M.H., LIM, O.T. A study on urea-water solution spray-wall impingement process and solid deposit formation in urea-SCR de-NOx system. Energies. 2019, 12(1), 1-18. https://doi.org/10.3390/en12010125

[27] SMITH, H., LAUER, T., SCHIMIK, V. et al. Evaluation and prediction of deposit severity in SCR systems. SAE International Journal of Engines. 2016, 9(3), 1735-1750. https://doi.org/10.4271/2016-01-0970

[28] TAN, L., FENG, P., YANG, S. et al. CFD studies on effects of SCR mixers on the performance of urea conversion and mixing of the reducing agent. Chemical Engineering and Processing: Process Intensification. 2018, 123, 82-88. https://doi.org/10.1016/j.cep.2017.11.003

[29] ZHANG, C., SUN, C., WU, M. et al. Optimisation design of SCR mixer for improving deposit performance at low temperatures. Fuel. 2019, 237, 465-474. https://doi.org/10.1016/j.fuel.2018.10.025

[30] ZUO, B., GOMES, A.M., RUTLAND, C.J. Modelling superheated fuel sprays and vaproization. International Journal of Engine Research. 2000, 1(4), 321-336. https://doi.org/10.1243/1468087001545218

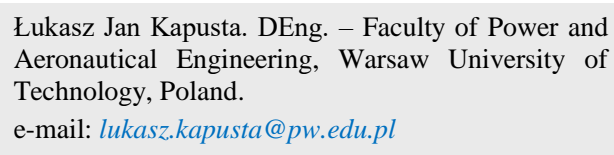

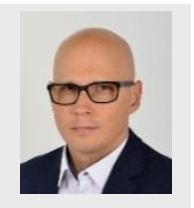

